\title{
Stenting treatment is a minimally traumatic and effective alternative to surgical repair for iatrogenic tracheobronchial lesion
}

\author{
Antonio D'Andrilli, Erino A. Rendina \\ Department of Thoracic Surgery, Sapienza University, Sant'Andrea Hospital, Rome, Italy \\ Correspondence to: Antonio D’Andrilli, MD. Department of Thoracic Surgery, Sapienza University, Sant'Andrea Hospital, Via di Grottarossa 1035, \\ 00189 Rome, Italy. Email: adandrilli@hotmail.com. \\ Provenance and Peer Review: This article was commissioned by the Editorial Office, fournal of Thoracic Disease. The article did not undergo external \\ peer review. \\ Comment on: Herrmann D, Volmerig J, Al-Turki A, et al. Does less surgical trauma result in better outcome in management of iatrogenic \\ tracheobronchial laceration? J Thorac Dis 2019;11:4772-81.
}

Submitted Dec 29, 2019. Accepted for publication Jan 29, 2020.

doi: $10.21037 /$ jtd.2020.01.48

View this article at: http://dx.doi.org/10.21037/jtd.2020.01.48

Iatrogenic tracheobronchial injuries are rare but lifethreatening events, most frequently due to complication of endotracheal intubation or percutaneous tracheostomy. Their incidence is low $(0.005-0.2 \%$ after double lumen or emergency single lumen intubation and up to $0.7 \%$ after percutaneous tracheostomy), but related mortality can be high and has been generally reported between $11 \%$ and $42 \%$ (1-5). Surgical repair has been considered the treatment of choice for a long time. More recently, along with the progressive evolution of interventional bronchoscopy, minimally invasive endoscopic treatment has gained diffusion as an effective alternative. In particular, increasing experience and technical improvement in airway stenting has significantly enlarged the spectrum of application of these techniques to treat tracheobronchial injuries. The same endoscopic techniques are employed to treat ischemic tracheobronchial lesions occurring after major lung surgery, which are usually more difficult to manage because of the potential extension of airway defects due to vascular insufficiency of the tracheobronchial wall after surgical dissection.

Due to only recent affirmation of endoscopic techniques as an alternative to surgical repair in this setting, literature data are still limited to few case series or isolated case reports, with lacking of generally agreed indications for conservative or endoscopic options.

Main criteria adopted to establish indications for treatment of iatrogenic tracheobronchial tears usually consider lesion depth and extension, presence of symptoms, patients' general status and need for mechanical ventilation (MV). Symptomatic, full-thickness tracheal wall lacerations are more frequently treated with surgical repair, especially if MV is needed $(1,2)$.

The retrospective study by Hermann and coll. (1) reports a series of 64 consecutive patients with post-intubation (56\%) or post-tracheostomy (44\%) tracheobronchial laceration who received surgical treatment in $67 \%$ of cases [43] and conservative bronchoscopic treatment with fibrin glue application in the remaining $33 \%$ of cases. Mean length of the airway lesion was 4 (range, 1-10) $\mathrm{cm}$ with $79 \%$ of patients presenting with a full-thickness tear. All patients with complete tracheal wall laceration received surgical treatment except for 5 of them who were treated conservatively because of stable clinical conditions. Surgical approach was transcervical in 29 patients and thoracotomy in 14 . The 30- and 90-day postoperative mortality in this series was $14.1 \%$, with all deaths occurred in patients receiving surgery and no mortality in the group receiving conservative bronchoscopic treatment. In this experience, surgical repair was considered indicated in all patients with complete (full-thickness) tracheal laceration and progressive symptoms or need for $\mathrm{MV}$, and in patients with concurrent esophageal injury or mediastinitis. Conservative management with bronchoscopic surveillance was reserved to patients with tracheal lesion up to the muscular wall and to selected patients with complete clinical stability despite 
the presence of a full-thickness airway lesion, but stenting was never used in the context of endoscopic management.

According to main findings of this study, sepsis and mediastinitis were the only signs correlating with mortality, and there was no difference in survival depending on the surgical approach or on the length of the injury.

Although precise indications for surgical treatment have been still not standardized, most authors in the literature consider full-thickness laceration, length over $4 \mathrm{~cm}$, concomitant esophageal injury, need for MV and presence of mediastinitis or progressive symptoms as the principal criteria to choose this approach $(1,2,6)$.

On the other hand, studies reporting series of patients receiving bronchoscopic treatment with stenting are still limited, but some recent experiences have shown that many of the above mentioned criteria to prefer surgical option are not absolute, and that endobronchial prosthesis can be effectively employed in a number of cases that have been traditionally considered as mandatory indications for surgery in the past $(3,7)$.

Tazi-Mezalek and coll. (3) have reported the results obtained on a series of 35 patients, $91.5 \%$ of which treated with endoscopic management. Only 3 out of 4 patients presenting with tracheo-esophageal fistula (TEF) underwent surgery. Overall success rate was $88.6 \%$ with $11.4 \%$ mortality rate. Surgery was avoided in almost all patients requiring $\mathrm{MV}$ by implanting a stent in case of lesion of the lower trachea or placing endotracheal tube cuff or tracheostomy cannula cuff distal to the injury, if located in the upper trachea. According to this experience, airway stenting should be considered also in ventilated patients, and surgery should be reserved for TEF and endoscopic management failure.

Over the last two decades we have successfully used self-expandable endo-tracheal and endo-bronchial stents in some patients with post-intubation tracheo-bronchial lesions and in a larger number of patients presenting with ischemic lesion of the bronchus or the trachea after major lung resection, even following bronchoplastic procedures (8-10). Endoscopically treated ischemic tracheobronchial lesions in our experience included bronchial stump dehiscences and even large damages of the tracheobronchial wall (9). Stenting was used for iatrogenic lesions only in case of full-thickness symptomatic laceration, while superficial lesions without related symptoms were always managed conservatively with bronchoscopic surveillance.

These bronchoscopic stenting techniques can be more easily applied in cases of post-intubation or post- tracheostomy airway injuries, because they are generally less likely to show a progressive enlargement of the defect compared with the ischemic lesions (11). The rationale of the stent treatment is to completely cover the airway laceration, thus excluding the airflow through the tracheobronchial tear and so favoring the healing of the airway wall promoted by the apposition of surrounding tissues. Necessary conditions for the final success of this technique are the following:

* Full and stable adherence of the expandable stent (usually fully covered nitinol stent) to the airway wall with complete covering of the defect. This result can be obtained only if the endobronchial prosthesis is of appropriate size and shape (conical or cylindrical) based on the defect extension and location, and if it is placed with both proximal and distal extremities lying on healthy tissue.

- Absence of local infection (mediastinitis or pleural empyema) outside the airway. Otherwise surgical treatment should be performed.

According to our experience, if the above mentioned conditions are completely satisfied, the stent technique may allow full recovery of most tracheobronchial iatrogenic airway lesions, even in patients with related symptoms, no clinical stability and need for MV, because once obtained effective coverage of the airway fistula, rapid improvement of respiratory and general conditions is frequently observed. Moreover, we believe that the presence of symptoms or need for MV should not be considered a contraindication to bronchoscopic approach, since the choice of a conservative treatment avoiding prolonged general anesthesia and heavy surgical procedures could be particularly advantageous to patients with compromised clinical status. Based on this principle, we agree with other authors (3) that surgery should be reserved for cases of unsuccessful bronchoscopic treatment or of TEF.

As also pointed out by other authors (12), we have identified the risk of stent migration as one of the most significant factors responsible for the bronchoscopic treatment failure. The use of anchoring systems to fix the prosthesis represents therefore a fundamental tip for the final success of the stent techniques. The placement of titanium helical fasteners that we have described (especially in the emergency setting) in previous publications $(8,9)$ has proved to be a safe and effective method to avoid stent dislocation and to increase the success rate of this technique in our experience.

In conclusion, according to our and other authors' recent experience, we believe that thanks to increasing expertise in operative bronchoscopy and stent techniques, the field of 
application of the endoscopic approach to treat iatrogenic tracheobronchial injuries is in progressive expansion, allowing successful minimally invasive management in a number of patients for whom surgical repair has been considered the sole effective treatment in the past.

\section{Acknowledgments}

Funding: None.

\section{Footnote}

Conflicts of Interest: Antonio D'Andrilli received lecture fee from Baxter. Erino A. Rendina has no conflicts of interest to declare.

Ethical Statement: The authors are accountable for all aspects of the work in ensuring that questions related to the accuracy or integrity of any part of the work are appropriately investigated and resolved.

Open Access Statement: This is an Open Access article distributed in accordance with the Creative Commons Attribution-NonCommercial-NoDerivs 4.0 International License (CC BY-NC-ND 4.0), which permits the noncommercial replication and distribution of the article with the strict proviso that no changes or edits are made and the original work is properly cited (including links to both the formal publication through the relevant DOI and the license). See: https://creativecommons.org/licenses/by-ncnd/4.0/.

\section{References}

1. Herrmann D, Volmerig J, Al-Turki A, et al. Does less surgical trauma result in better outcome in management of iatrogenic tracheobronchial laceration? J Thorac Dis 2019;11:4772-81.

2. Schneider T, Storz K, Dienemann H, et al. Management

Cite this article as: D'Andrilli A, Rendina EA. Stenting treatment is a minimally traumatic and effective alternative to surgical repair for iatrogenic tracheobronchial lesion. J Thorac Dis 2020;12(3):137-139. doi: 10.21037/jtd.2020.01.48 of iatrogenic tracheobronchial injuries: a retrospective analysis of 29 cases. Ann Thorac Surg 2007;83:1960-4.

3. Tazi-Mezalek R, Musani AI, Laroumagne S, et al. Airway stenting in the management of iatrogenic tracheal injuries: 10-year experience. Respirology 2016;21:1452-8.

4. Leinung S, Möbius C, Hofmann HS, et al. Iatrogenic tracheobronchial ruptures - treatment and outcomes. Interact Cardiovasc Thorac Surg 2006;5:303-6.

5. Hofmann HS, Rettig G, Radke J, et al. Iatrogenic ruptures of the tracheobronchial tree. Eur J Cardiothorac Surg 2002;21:649-52.

6. Lee SK, Kim DH, Lee SK, et al. Does surgical repair still have a role for iatrogenic tracheobronchial rupture? Clinical analysis of a thoracic surgeon's opinion. Ann Thorac Cardiovasc Surg 2016;22:348-53.

7. Lee BE, Korst RJ. Successful treatment of an iatrogenic tracheal laceration with a temporary polyurethane-coated nitinol stent. Ann Thorac Surg 2016;102:e11-2.

8. Andreetti C, D'Andrilli A, Ibrahim M, et al. Effective treatment of post-pneumonectomy bronchopleural fistula by conical fully covered self-expandable stent. Interact Cardiovasc Thorac Surg 2012;14:420-3.

9. D'Andrilli A, Andreetti C, Menna C, et al. Successful endoscopic treatment of severe ischemic damage of the bronchus. J Thorac Cardiovasc Surg 2017;154:e17-9.

10. Menna C, Poggi C, Ibrahim M, et al. Coated expandable metal stents are effective irrespective of airway pathology. J Thorac Dis 2017;9:4574-83.

11. Andreetti C, D’Andrilli A, Ibrahim M, et al. Submucosal injection of the silver-human albumin complex for the treatment of bronchopleural fistula. Eur J Cardiothorac Surg 2010;37:40-3.

12. Dutau H, Breen DP, Gomez C, et al. The integrated place of tracheobronchial stents in the multidisciplinary management of large post-pneumonectomy fistulas: our experience using a novel customised conical selfexpandable metallic stent. Eur J Cardiothorac Surg 2011;39:185-9. 